\title{
Field tracer tests on the mobility of natural organic matter in a sandy aquifer
}

\author{
J. F. McCarthy, ${ }^{1}$ B. Gu, ${ }^{1}$ L. Liang, ${ }^{1}$ J. Mas-Pla, ${ }^{2}$ \\ T. M. Williams, ${ }^{3}$ and T.-C. J. Yeh ${ }^{4}$
}

\begin{abstract}
The field-scale transport of natural organic matter (NOM) was examined in a two-well forced gradient injection experiment in a sandy, coastal plain aquifer in Georgetown, South Carolina. Spatial moments described the migration of the center of mass of NOM and conservative tracer. Temporal moments were used to estimate mass loss and retardation of the NOM along a transect of six sampling locations at two depths and at the withdrawal well. Large differences were observed in transport behavior of different subcomponents of NOM. Larger and more strongly binding NOM components in the injection solution are postulated to adsorb and displace weakly binding, low-molecular weight NOM in groundwater. Conversely, NOM components that were similar to the groundwater NOM were transported almost conservatively, presumably due to "passivation" of the aquifer by previously adsorbed components of the groundwater NOM. NOM may thus exhibit two types of effects on contaminant dynamics in the subsurface. When the equilibria between solution and solid phase NOM is disrupted by introduction of a novel source of NOM, descriptions of the multicomponent transport process are complex and predictive modeling is problematic. Because of the differences in transport behavior of NOM subcomponents, the chemical properties and, more importantly, the functional behavior of NOM with respect to contaminant migration will vary with time and distance along a flow path. However, when groundwater NOM exists at a steady state with respect to adsorption on aquifer surfaces, the migration of NOM, and the contaminant-NOM complex, may be approximated as the transport of a conservative solute.
\end{abstract}

\section{Introduction}

In August-September 1992, we conducted a forced gradient injection of natural organic matter (NOM) at a wellcharacterized field site in a sandy Atlantic coastal plain aquifer in Georgetown, South Carolina [Mas-Pla, 1993; Yeh et al., 1995]. The overall goal of this research is to understand, and to develop a capability to predict, the transport of NOM. The motivation for studying NOM transport derives from its potential effect on the subsurface transport of contaminants, including metals and radionuclides as well as higher molecularweight organic contaminants [McCarthy and Zachara, 1989]. Laboratory studies have demonstrated that NOM can affect contaminant mobility by enhancing transport of contaminants that bind to mobile NOM in groundwater [Dunnivant et al., 1992b; Magee et al., 1991]. Conversely, contaminants may be further retarded if the NOM introduced to an aquifer adsorbs to the solid phase and thereby increases its affinity to bind contaminants [Zsolnay, 1993; Murphy et al., 1994]. NOM can

\footnotetext{
${ }^{1}$ Environmental Sciences Division, Oak Ridge National Laboratory, Oak Ridge, Tennessee.

${ }^{2}$ Department de Geologia, Universitat Autonoma de Barcelona, Spain.

${ }^{3}$ Baruch Forest Science Institute, Clemson University, Clemson, South Carolina.

${ }^{4}$ Department of Hydrology and Water Resources, University of Arizona, Tucson.

Copyright 1996 by the American Geophysical Union.

Paper number 96WR00285.

0043-1397/96/96WR-00285\$09.00
}

also have an indirect influence on contaminant migration through its effect on the colloidal stability of inorganic colloids. Adsorption of NOM can promote the mobilization [Ryan and Gschwend, 1990] and stability [Amirbahman and Olson, 1993] of colloids within an aquifer and thereby potentially facilitate the transport of contaminants adsorbed on the mobile colloids. Although these laboratory studies are important to understand the adsorption of NOM on model minerals and aquifer sediments, field-scale transport experiments are necessary to reveal "ground truth" which tests understanding of NOM transport and its potential role in contaminant transport.

Specific objectives of this field experiment were to determine the extent to which the field-scale transport of NOM conforms to behavior predicted from laboratory understanding. NOM was hypothesized to be transported as a multicomponent mixture. Adsorption was postulated to decrease over time as aquifer surfaces became covered by adsorption of NOM. Desorption was predicted to be limited, especially for NOM components with a high affinity for aquifer sites. We also wished to evaluate the appropriateness of simple models to describe the transport of NOM. Another objective of the field research was to focus laboratory investigations on key processes controlling transport behavior in natural subsurface systems. Discrepancies between laboratory predictions and field observation may point out additional processes that were not previously hypothesized to be critical to transport.

A previous injection of NOM in 1990 at an adjacent field site clearly demonstrated preferential transport of some NOM subcomponents [McCarthy et al., 1993]. However, owing to limited information on the flow field [Mas-Pla et al., 1992], it was not 

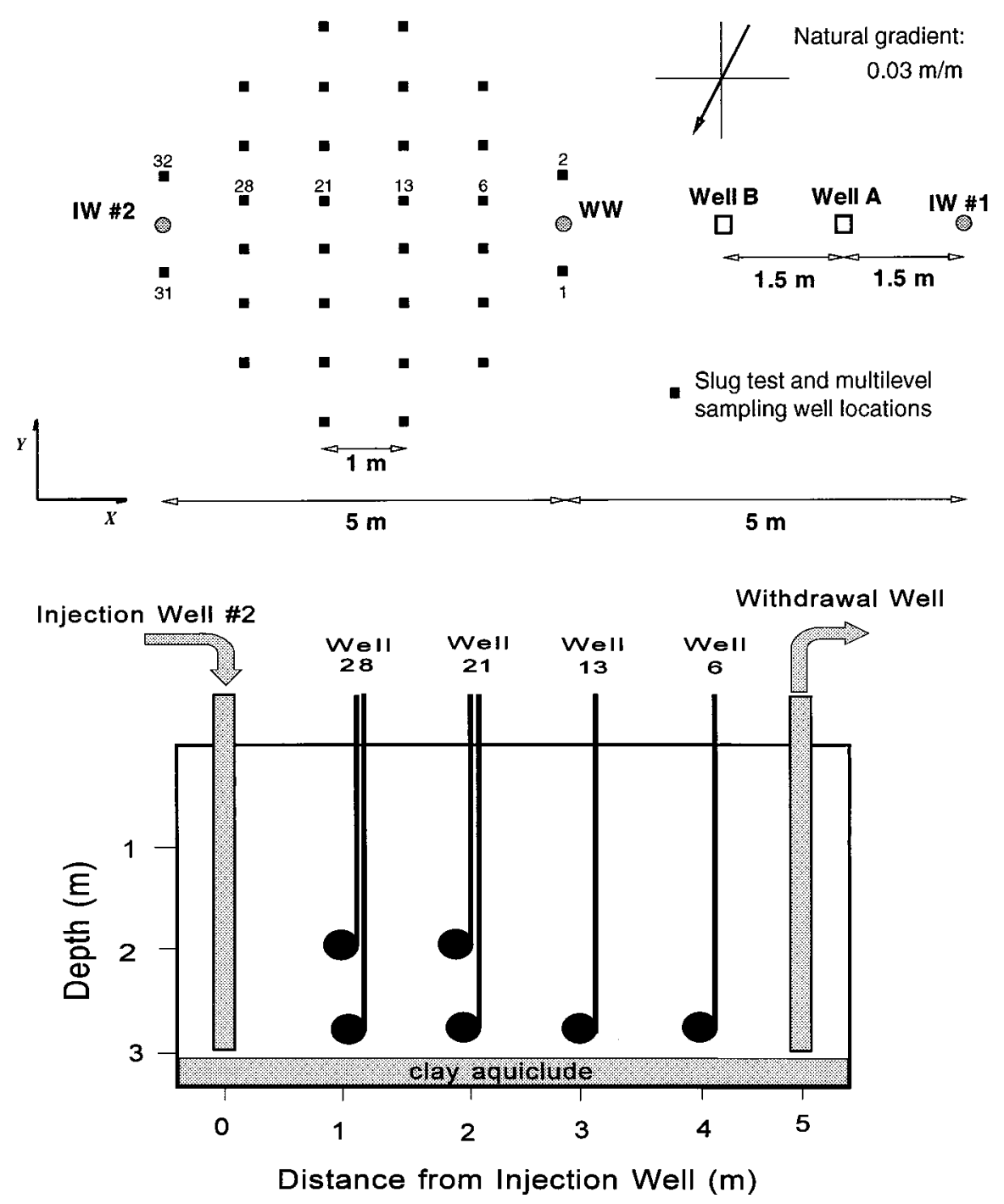

Figure 1. (top) Plan view of experimental site and (bottom) a cross section of point breakthrough sampling locations.

possible to reliably estimate the extent of retardation of the injected NOM and the amount of mass lost due to adsorption. Likewise, issues of kinetic limitations and changes in adsorption over time could not be resolved with any confidence $[M c$ Carthy et al., 1993]. Furthermore, in 1990 there was no attempt to remove dissolved oxygen (DO) from the NOM solution that was injected into the suboxic, $\mathrm{Fe}$ (II)-rich aquifer, and precipitation of iron-(hydr)oxides from Fe(II) [Liang et al., 1993a, b] may have created new surfaces for the adsorption of NOM during that experiment. To overcome these obstacles, in the 1992 experiment described here, dissolved oxygen was removed from all solutions injected into the aquifer. The site was also extensively characterized with respect to the threedimensional spatial distribution of hydraulic conductivity to reduce uncertainty arising from hydrologic heterogeneity [Mas-Pla, 1993; Yeh et al., 1995]. Nonreactive tracer tests demonstrated that a three-dimensional finite element model for flow and transport based on the extensive hydraulic conductivity data set adequately reproduced the flow field. Further, our prior simulations indicated that information was needed on both the behavior of the centers of mass of the nonreactive tracer and the NOM, as well as more detailed histories of the concentration and composition of mobile NOM at monitoring wells. The migration of the plume of NOM and the conservative tracer was measured at 128 sampling locations and described using spatial moments analysis. Concentration histories and the size distribution of NOM were measured for a transect of six sampling locations at two depths and at the withdrawal well, and temporal moments were used to estimate mass loss and retardation of the NOM. The integrated behavior of the plume is represented by the breakthrough curves observed at the withdrawal well.

\section{Methods and Materials}

Description of the field experiment. A detailed description of the field site for the two-well forced gradient experiment is presented in previous papers [Williams and McCarthy, 1991; McCarthy et al., 1993; Mas-Pla, 1993; Yeh et al., 1995]. Figure 1 depicts the location of the injection and withdrawal wells (IW 2 and WW, respectively) and the sampling wells. A multilevel sampling assembly with O-ring packers was inserted into each fully screened sampling well (numbered 1-32; Figure 1) to permit sampling at five depths in each well. A forced gradient 
was established by injecting groundwater from a supply well located approximately $100 \mathrm{~m}$ from the injection well, while water from the withdrawal well was discarded downgradient.

After a steady state flow regime was established, simultaneous injection of chloride and NOM for 659 hours was initiated, followed by injection of the groundwater from the supply well to maintain the hydrologic gradient until the end of the experiment at 43 days. The source of the NOM was a wetlands pond draining a mixed hardwood forest near the site. The "brown water" contains high levels of NOM $\left(66 \mathrm{mg} \mathrm{C} \mathrm{L}^{-1}\right)$. Its chemical properties and adsorption behavior are described by Gu et al. [1994, 1995]. In brief, the Fourier transform infrared (FTIR) and nmr spectra of the NOM resemble those of humic substances found in aquatic systems and soil fulvic acids [Stevenson and Goh, 1971; Thurman, 1985]. The NOM is rich in O-containing functional groups such as - $\mathrm{COOH}$ and $-\mathrm{OH}$, and its adsorption behavior is similar to Swannee River fulvic acid [Gu et al., 1994]. The pond water was transferred to a Vitonlined enclosure at the injection site and was recirculated continuously before and during the injection. Prior to being injected, the "brown water" from the pond was diluted by mixing in-line with an equal volume of groundwater from the supply well. The chemical composition of the NOM injection solution is similar to that of the groundwater at the injection site (Table 1a), although the groundwater was somewhat higher in calcium, alkalinity, and $p \mathrm{H}$. Mechanical problems with valves resulted in occasional "spikes" in the NOM concentration. Chloride was mixed in-line using a metering pump, but mechanical problems with pumps resulted in erratic levels of chloride in the injection solution [Yeh et al., 1995]. All solutions entering the injection well were filtered through a series of filters to a final membrane filter with a $0.2-\mu \mathrm{m}$ pore size (Water Equipment Technology, West Palm Beach, Florida) and then oxygen was removed using a air stripper constructed of 8 -inch-diameter PVC pipe containing a 65 -inch length of plastic Koch/Sultzer structured packing (Koch Engineering, Witchita, Kansas). Nitrogen gas was introduced at a flow rate of approximately $10 \mathrm{~L} \mathrm{~min}{ }^{-1}$ into the bottom of the stripper column while water flowed down the packing at a rate of approximately $3 \mathrm{~L} \mathrm{~min}^{-1}$. Filtered, oxygen-depleted water was then injected into the well. The air stripper was successful in

Table 1a. Aqueous Chemistry of Groundwater and NOM Injection Solution

\begin{tabular}{lcc}
\hline $\begin{array}{c}\text { Chemical } \\
\text { Measured }\end{array}$ & $\begin{array}{c}\text { Groundwater } \\
\mathrm{mg} \mathrm{L}^{-1}\end{array}$ & $\begin{array}{c}\text { NOM Injection } \\
\text { Solution, } \\
\mathrm{mg} \mathrm{L}^{-1}\end{array}$ \\
\hline Alkalinity & 132 & $<20$ \\
$\mathrm{Ca}$ & 30 & 13 \\
$\mathrm{Cd}$ & 0.002 & 0.001 \\
$\mathrm{Cl}$ & 17 & 25 \\
$\mathrm{Cu}$ & 0.25 & 0.25 \\
$\mathrm{~F}$ & 0.6 & 0.5 \\
$\mathrm{~K}$ & 0.7 & 0.7 \\
$\mathrm{Mg}$ & 1.2 & 1.3 \\
$\mathrm{Na}$ & 10 & 10 \\
$\mathrm{~Pb}$ & 0.032 & 0.007 \\
$\mathrm{SO}$ & 13 & $<5$ \\
$\mathrm{Zn}$ & 0.01 & 0.02 \\
$\mathrm{NO}_{3}$ & $<0.1$ & 0.2 \\
$\mathrm{pH}$ & 8.0 & 7.1 \\
Turbidity & 0.17 & 0.19 \\
Total solids & 173 & 200 \\
\hline
\end{tabular}

Table 1b. Dissolved Oxygen Levels During the NOM Injection

\begin{tabular}{cccc}
\hline Well & $\begin{array}{c}\text { Depth, } \\
\mathrm{m}\end{array}$ & $\begin{array}{c}\text { Distance, } \\
\mathrm{m}\end{array}$ & $\begin{array}{c}\text { Dissolved } \\
\text { Oxygen, } \\
\mu \mathrm{g} \mathrm{L}^{-1}\end{array}$ \\
\hline $\begin{array}{ccc}\text { Injection } \\
28\end{array}$ & $\ldots .0$ & 0.0 & $387.4 \pm 41.8$ \\
21 & 2.6 & 1.0 & $256.0 \pm 61.7$ \\
13 & 2.6 & 2.0 & $215.5 \pm 91.4$ \\
6 & 2.6 & 3.0 & $6.1 \pm 5.2$ \\
28 & 2.6 & 4.0 & $3.1 \pm 2.5$ \\
21 & 2.0 & 1.0 & $3.2 \pm 2.6$ \\
WW & 2.0 & 2.0 & $2.2 \pm 0.7$ \\
& $\cdots$ & 5.0 & $1.72 \pm 0.45$ \\
\hline
\end{tabular}

reducing the levels of DO in the injection solution from saturation to $<0.4 \mathrm{mg} \mathrm{L}^{-1}$ (Table $1 \mathrm{~b}$ ). The DO levels in the point sampling wells and the withdrawal well remained very low $\left(<10 \mu \mathrm{g} \mathrm{L}^{-1}\right)$ throughout the experiment, except at the two closest wells at the 2.6-m depth (Table 1b).

Eighteen concentration "snapshots" of the three-dimensional plume of NOM and chloride were sampled in 128 multilevel sampling ports. A vacuum manifold system sampled all ports within a 20 -min period, and each snapshot was considered instantaneous. In addition, continuous breakthrough data were also collected at the withdrawal well and at six sampling wells in a transect between the injection and withdrawal wells (wells 6, 13, 21, and 28 at $2.6 \mathrm{~m}$ depth, and wells 21 and 28 at $2.0 \mathrm{~m}$ depth; Figure 1). Groundwater from these sampling ports was collected using a peristaltic pump at a flow rate of 50 $\mathrm{mL} \min ^{-1}$. Polyethylene capillary tubing inside the well was connected at the wellhead to $0.63-\mathrm{cm}$ OD Tygon tubing which was wrapped in latex rubber tubing to minimize diffusion of oxygen and prevent precipitation of ferric oxide artifacts. The latex-coated sample lines were also encased in two thicknesses of neoprene pipe insulation to minimize temperature changes during collection of the sample.

Analyses of groundwater samples. Water quality parameters were measured before water contacted the atmosphere. Specific conductance, $p \mathrm{H}$, and electrode potential were measured by immersing the probes in a narrow funnel connected to the sample line so that fresh sample contacted the probes and overflowed the funnel. DO was measured using CHEMetric ampules (CHEMetrics, Inc., Calverton, Virginia). Samples for $\mathrm{NOM}$ analyses were preserved with $\mathrm{HNO}_{3}$ to $p \mathrm{H}$ 2.3. NOM concentrations were measured using a Shimadzu Model 5000 high-temperature combustion total organic carbon analyzer, and concentrations are reported as $\mathrm{mg} \mathrm{C} \mathrm{L}^{-1}$. Chloride was measured using a Technicon Autoanalyzer.

For analysis of different size fractions of NOM, water was filtered on-line using Amicon Spiral Filters (3000 and 100,000 Dalton molecular weight). Filters were purged with nitrogen and connected in-line to the groundwater sampling tubes. Samples were collected and analyzed as described previously [Mc Carthy et al., 1993].

\section{Modeling Approach}

The extensive hydrological site characterization [Mas-Pla, 1993; Yeh et al., 1995] indicated a complex hydrological heterogeneity at the $5 \mathrm{~m} \times 5 \mathrm{~m}$ experimental site for the tracer test. Yeh et al. [1995] demonstrated that a fully three-dimensional 

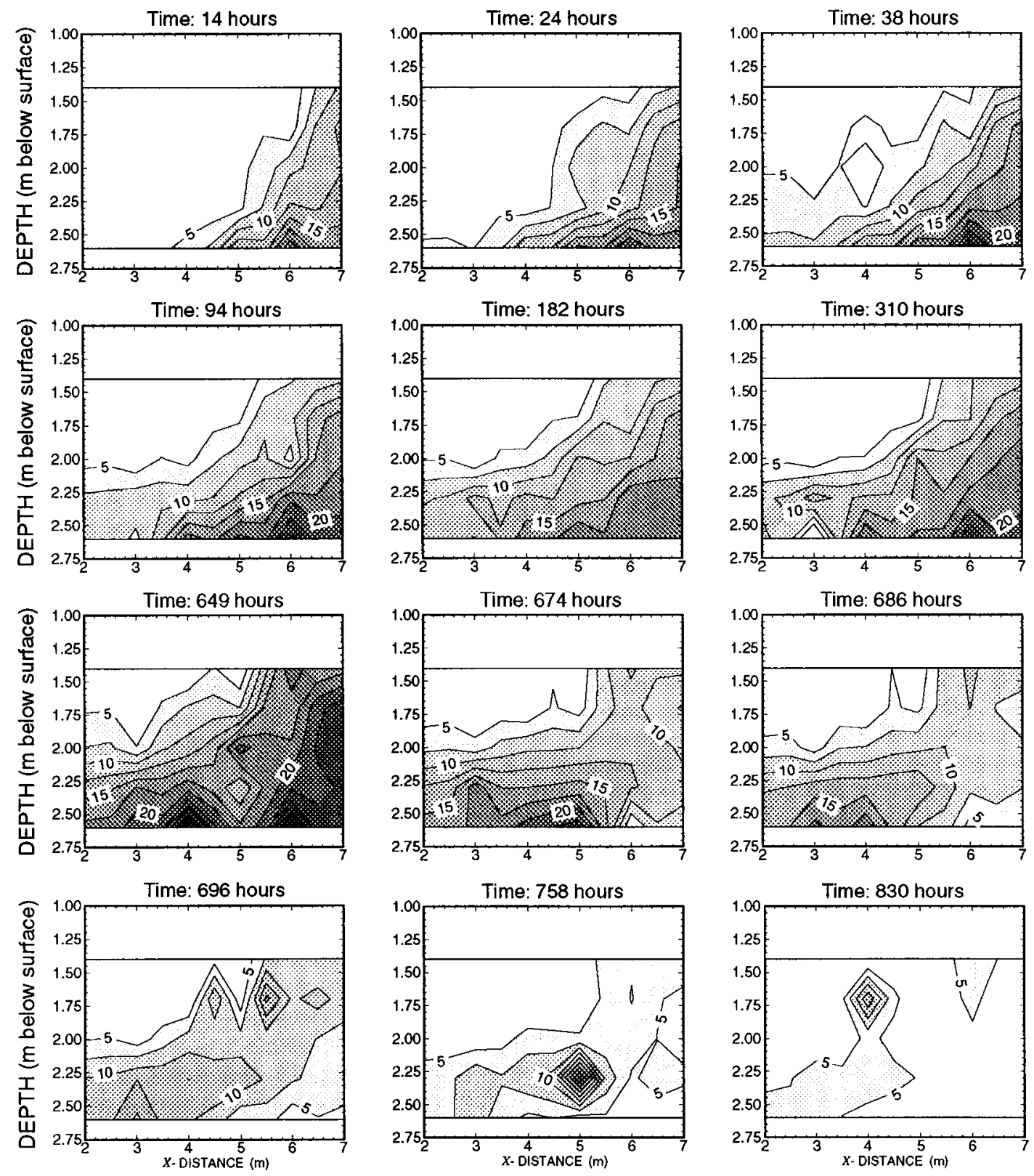

Figure 2. Observed NOM distribution in a cross section along the coordinate $Y=3.2 \mathrm{~m}$ (Figure 1) at different observation times. Contour lines are given in $\mathrm{mg} \mathrm{C} \mathrm{L}^{-1}$ and contour line equidistance is $5 \mathrm{mg} \mathrm{C} \mathrm{L}^{-1}$.

flow and solute transport model (MMOC3 [Srivastava and Yeh, 1992]) along with the three-dimensional hydraulic conductivity information are necessary to reproduce the complex pattern of the chloride plume at the experimental field site. Because mechanical problems described above, input concentrations were different for chloride and NOM [Yeh et al., 1995], making it difficult to use the actual chloride plume as a reference for understanding the rates of transport and mass loss of NOM in the aquifer. We therefore simulated the plume of a conservative tracer originating from an identical step input as the injected NOM so that the adsorptive behavior of NOM could be compared with the nonreactive solute. The simulation followed the approach described by Yeh et al. [1995], and the variable input concentration of NOM was included in the timedependent concentration boundary defined at the injection well.
Analysis of spatial moments and retardation. Spatial zeroth and first moments of the eighteen snapshots of the threedimensional plumes of chloride and NOM were analyzed. The procedure for the moments analysis is identical to that by Yeh et al. [1995]. Briefly, the zeroth moment represents the mass of the three-dimensional plume at a given observation time, and the first spatial moment provides the coordinates $\left(x_{c}, y_{c}\right.$, and $z_{c}$ ) of the center of mass in the aquifer. It should be pointed out that large sampling errors are expected in this analysis due to field heterogeneity, insufficient sampling network, interpolation and extrapolation schemes, etc. This type of error has been reported in other well-known field-scale tracer experiments such as Borden, Cape Cod, and Columbus; detailed discussions are available from Rajaram and Gelhar [1991] and Boggs and Adams [1992].

An empirical or apparent retardation of NOM, $R^{*}$, is de- 

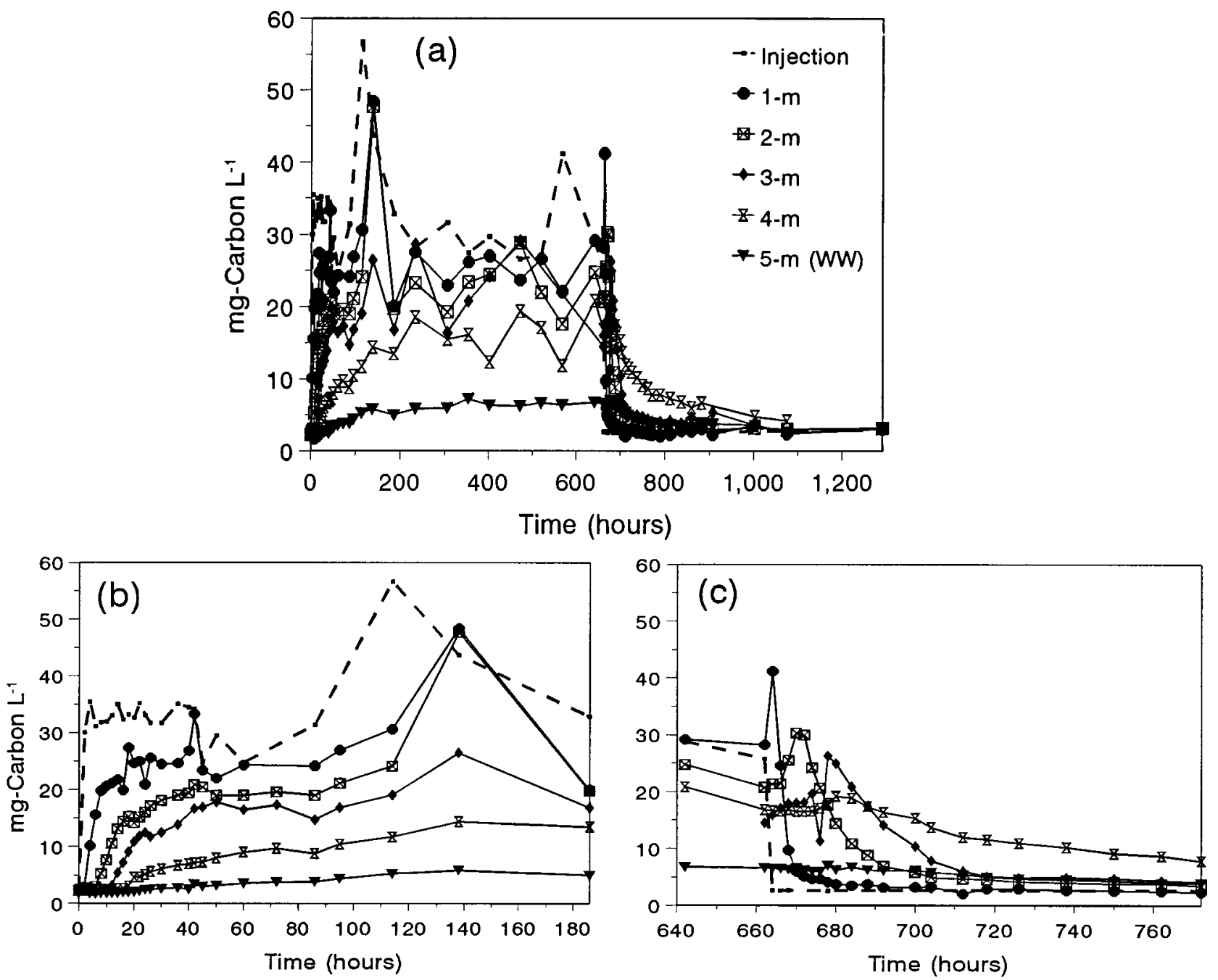

Figure 3. (a) Concentration histories of NOM at the 2.6-m depth for the injection solution, the sampling points located 1, 2, 3, and $4 \mathrm{~m}$ from the injection point (wells 28, 21, 13, and 6, respectively; Figure 1), and the withdrawal (WW) well located $5 \mathrm{~m}$ from the injection well. (b) The initial 200 hours of the breakthrough curve. (c) The decrease in NOM concentration when the source was changed from the NOM solution to the groundwater with low levels of NOM at 659 hours.

fined as the ratio of the average travel times, $\bar{t}$, of the observed NOM and simulated chloride plumes, based on their temporal moments [Roberts et al., 1986]:

$$
R^{*}=\bar{t}_{\mathrm{NOM}} / \bar{t}_{\mathrm{Cl}^{-}}
$$

$R^{*}$ does not assume sorption equilibrium and is dependent on the relative rates of hydrological and chemical processes. The mean average travel time, $\bar{t}$, is calculated as the mean of the breakthrough concentrations of NOM or chloride:

$$
\bar{t}=\left(\sum_{i=1}^{n} C_{i} t_{i}\right) /\left(\sum_{i=1}^{n} C_{i}\right)
$$

where $C_{i}$ is the concentration (above background) at the sampling time $t_{i}$. Since the time span for the step input is relatively large, the mean travel times must be corrected by subtracting the mean time of the correspondent step input [Valocchi, 1985]:

$$
\bar{t}_{A}=\bar{t}_{A}(\mathrm{btc})-\bar{t}_{A}(\text { input })
$$

where for the solute $A, \bar{t}_{A}$ (input) and $\bar{t}_{A}$ (btc) are the centers of mass of the step input and observed breakthrough curve, respectively.

\section{Results and Discussion}

General behavior of the NOM plume. A cross section (at $y=3.2 \mathrm{~m}$ ) of the NOM distribution is plotted in Figure 2 for 12 different observation times. As expected, NOM migration, like that of the nonreactive tracer, was controlled by the hydrologic characteristics of the site. For example, the concentration front moved faster through the bottom layers, and the top central areas of low conductivity [Yeh et al., 1995] retarded the movement and produced a lateral spread of the solute [Mas-Pla, 1993].

The concentration histories of NOM at the withdrawal wells and at the four sampling points at the 2.6-m depth are shown in Figure 3, and data for the two sampling points at the $2.0-\mathrm{m}$ depth are shown in Figure 4. NOM breakthrough curves exhibit expected behavior: at progressively more distant wells 

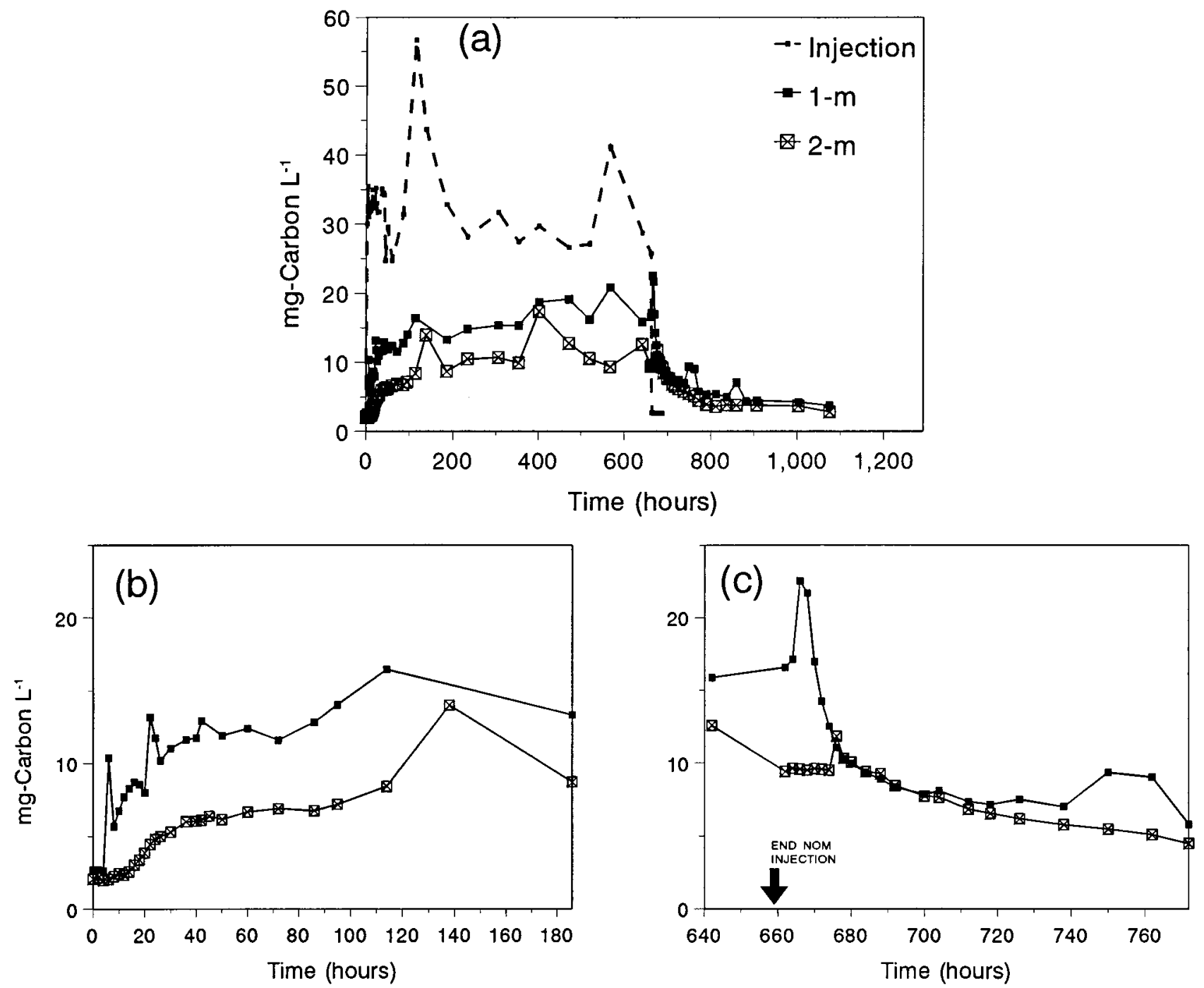

Figure 4. (a) Concentration histories of NOM at the 2.0-m depth for the injection solution and the sampling points located 1 and $2 \mathrm{~m}$ from the injection point (wells 28 and 21, respectively). (b) The initial 200 hours of the breakthrough curve. (c) The decrease in NOM concentration when the source was changed from the NOM solution to the groundwater with low levels of NOM at 659 hours.

within the same layer, arrival times are later and peaks are broader and flatter. NOM arrival is delayed, and the concentration of NOM is substantially lower, in wells at the $2.0-\mathrm{m}$ depth (Figure 4) than in wells equally distant at the $2.6-\mathrm{m}$ depth (Figure 3). The slower arrival is related to the slower flow rates in the $2.0-\mathrm{m}$ layer. The lower concentration may be caused by the greater adsorptive capacity of the aquifer material at the 2.0-m depth [McCarthy et al., 1993]. However, the lower NOM levels may also be due to greater hydrodynamic dispersion; the dispersion may arise more from the larger degree of spatial variability in hydraulic conductivity in this layer than the effect of the lower velocity [Yeh et al., 1995]. When the NOM injection was terminated at 659 hours, the concentration of NOM declined rapidly.

Comparison of the observed NOM and the simulation of a nonreactive tracer with the same step input form as the NOM (Figure 5) illustrates adsorptive losses of NOM along the flow path (decrease in the height of the NOM plateau relative to chloride), and a "smoothing" of the breakthrough curves for the reactive tracer (the conservative tracer clearly tracks the input concentration peaks, whereas not all of them are recognized in the NOM curves). NOM desorption curves at all wells, but especially at 2.6-m depth in wells 28,21 , and 13 , are close to those of the conservative solute, suggesting that NOM desorption is limited.

The cumulative concentrations of the simulated conservative tracer and observed NOM are compared in Figure 6. The angle of separation of the observed NOM data from the 1:1 line represents the cumulative adsorbed concentration (i.e., the amount of NOM removed from solution, relative to the conservative tracer concentration). The amount of NOM retained by the aquifer increases with distance from the source. It is also significant that slopes of the observed NOM tend to increase slightly (i.e., toward the 1:1 dotted line), indicating a decrease in adsorption over time. The smaller slope (greater adsorbed mass) at $2.0-\mathrm{m}$ depth than at $2.6 \mathrm{~m}$ is consistent with the larger adsorption capacity at this layer.

The change in adsorption behavior over time and distance can also be illustrated by comparing the observed data with a model simulation that assumes that the aquifer is homoge- 

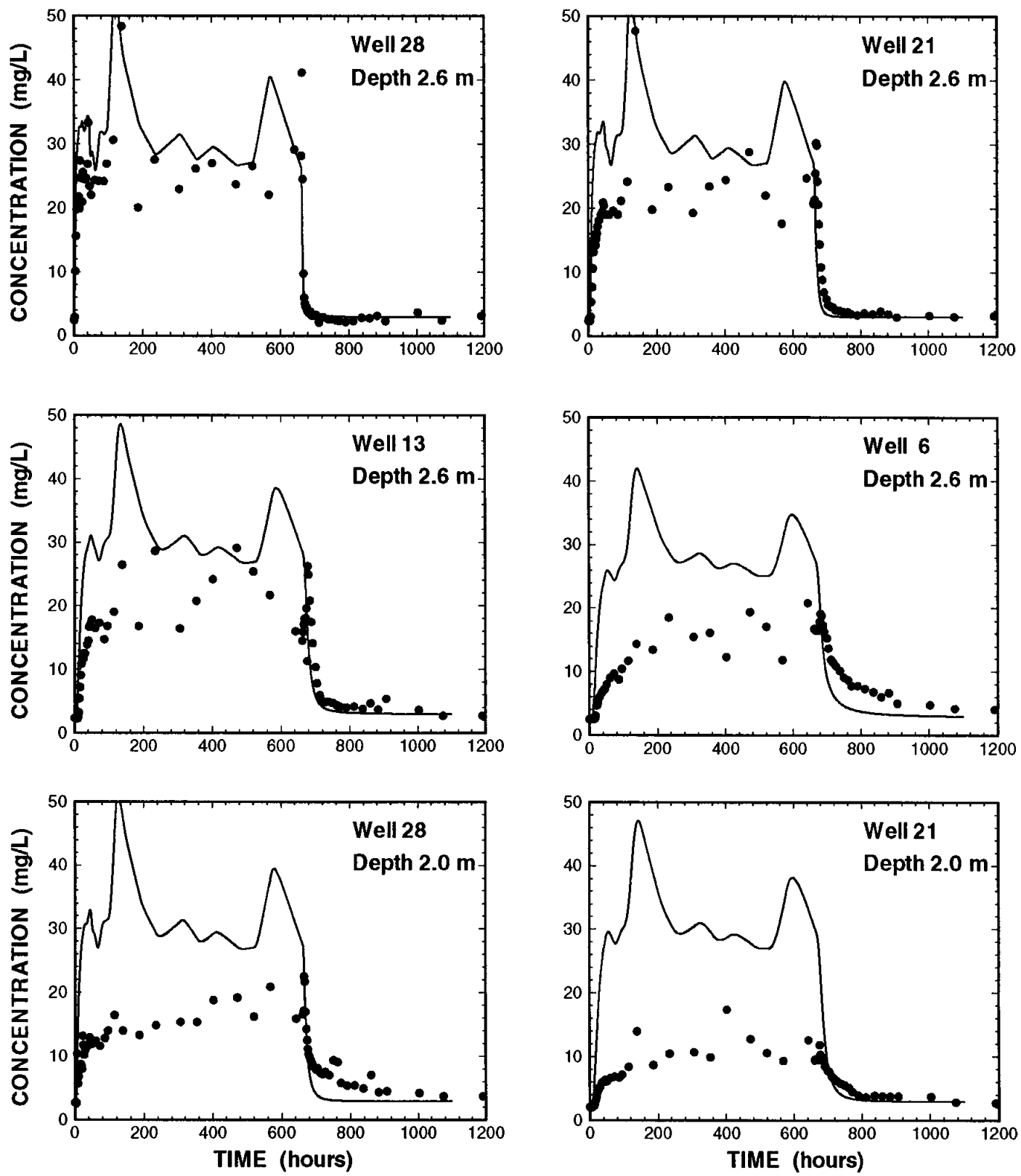

Figure 5a. Observed NOM concentration histories (solid circles) and simulated breakthrough for a conservative tracer with an identical step input form as the NOM injection (curve) for the six point breakthrough sampling locations.

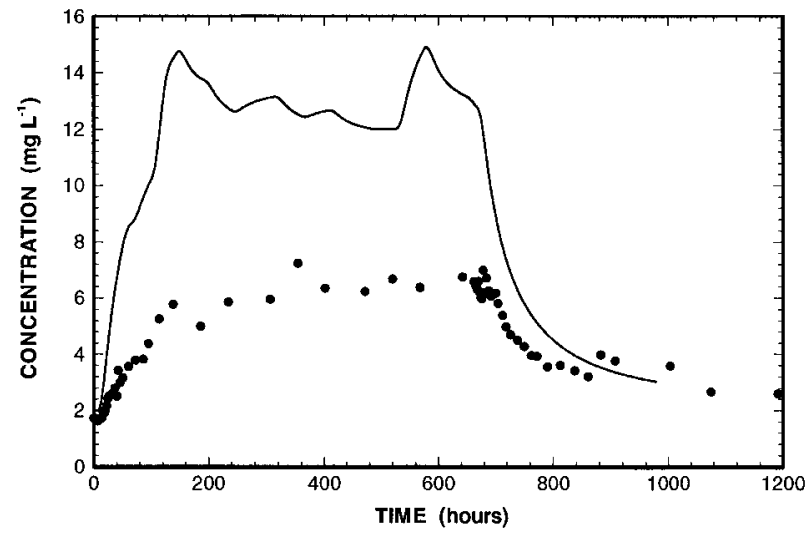

Figure 5b. Same as Figure 5a, except for the withdrawal well. neous with respect chemical properties and treats NOM as a single compound without consideration of it chemical heterogeneity. The three-dimensional simulation approach was employed for the simulation of NOM transport, with a chemical sorption model previously used to describe NOM transport [Jardine et al., 1992; Mas-Pla, 1993] included in the numerical model. The amount of NOM adsorbed to the aquifer was modeled by a two-site sorption: Type 1 sites are assumed to be instantaneous and reversible, while type 2 sites follow reversible first-order kinetics with respect to the adsorbed solute mass [Cameron and Klute, 1977]. The velocity field and boundary and initial conditions were identical to that of the simulation for chloride during August-September 1992 [Yeh et al., 1995] (see Mas-Pla [1993] for details), except that the NOM injection concentration (Figure 3) was used at the injection 

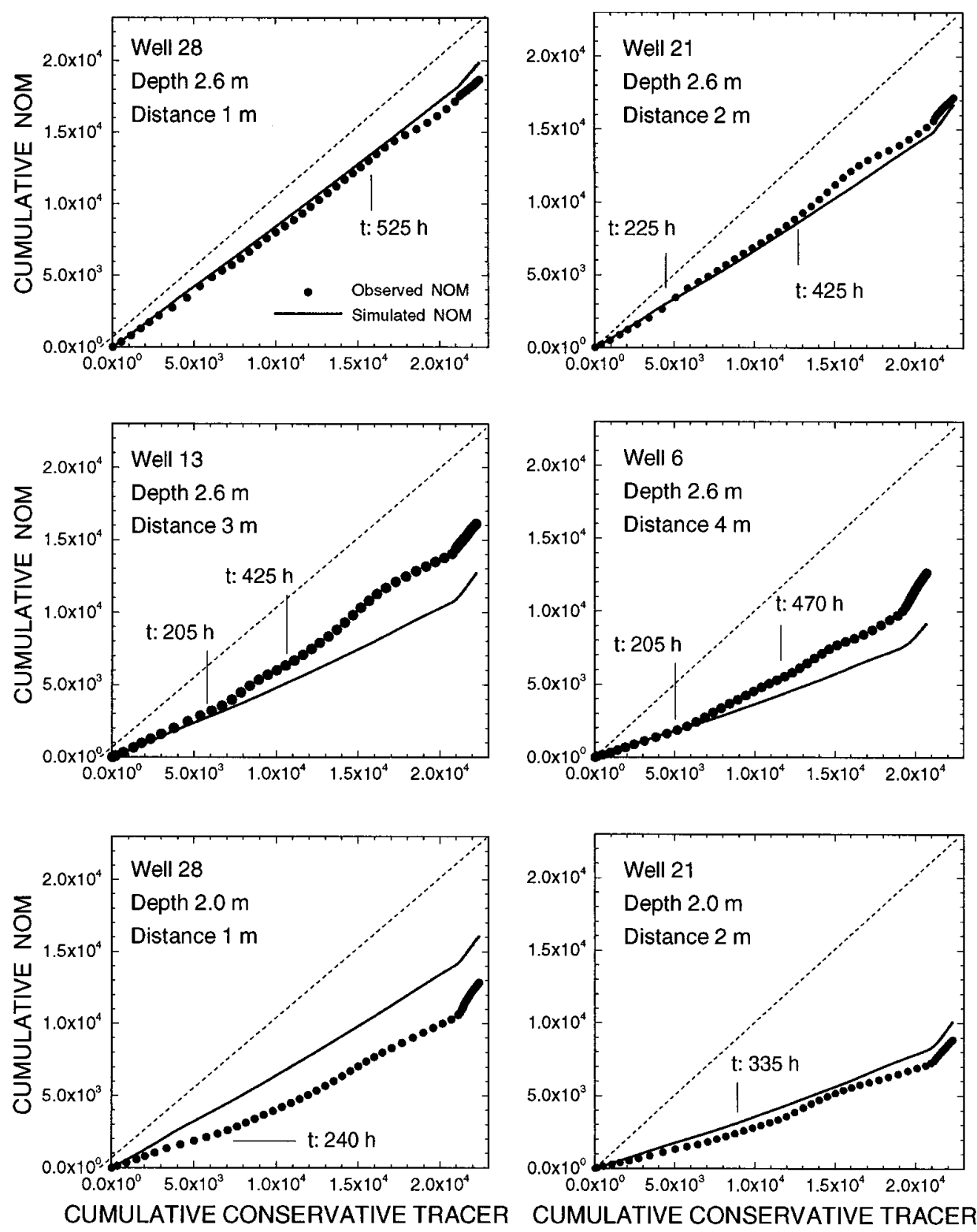

Figure 6a. Cumulative concentration of the conservative tracer versus the cumulative concentration of the observed (solid circles) and simulated (solid line) NOM at the six point breakthrough sampling locations.

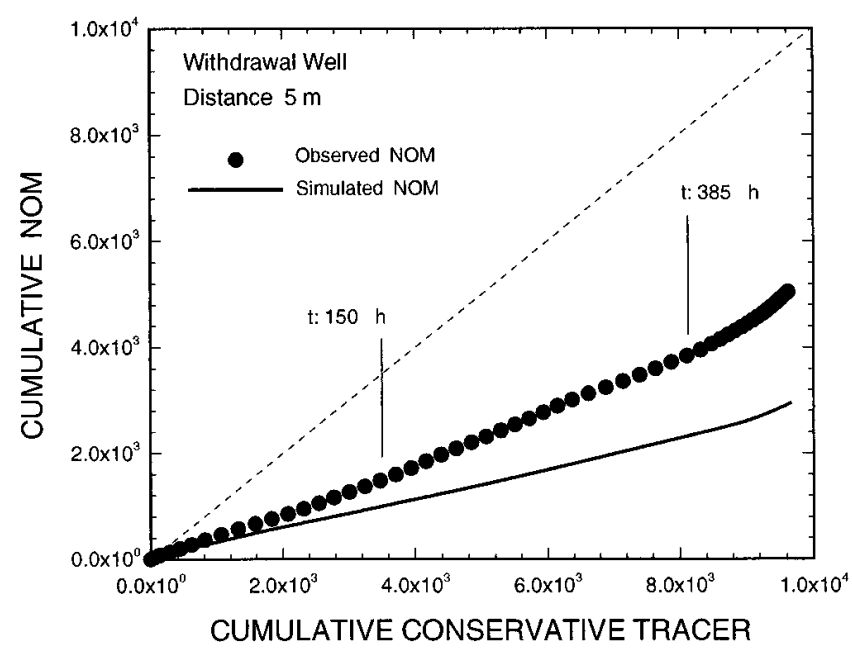

Figure 6b. Same as Figure 6a, except for the withdrawal well. well. The model was calibrated to fit the observed NOM breakthrough data at well 28, 2.6-m depth. The adsorption and desorption rate coefficients selected to represent the breakthrough at that location were then used to simulate breakthrough at all the other wells.

As a first approximation, the two-site adsorption model reproduced the shape of the breakthrough curves reasonably well (Figure 7). For example, curves at 2.6-m depth in wells 28 and 21 have their adsorption and desorption limbs and plateau correctly represented. For the first 200 hours, observed and simulated curves were also acceptable at wells 13 and 6 and the withdrawal well. However, it is the pattern of discrepancies between the observed data and the model that reveal some interesting features of NOM transport that are independent of the values of the coefficients used in the simulations. Differences between observed and simulated curves indicate that a single set of coefficients is not able to simulate each one of the observed curves at $2.60-\mathrm{m}$ depth. For example, the height of 

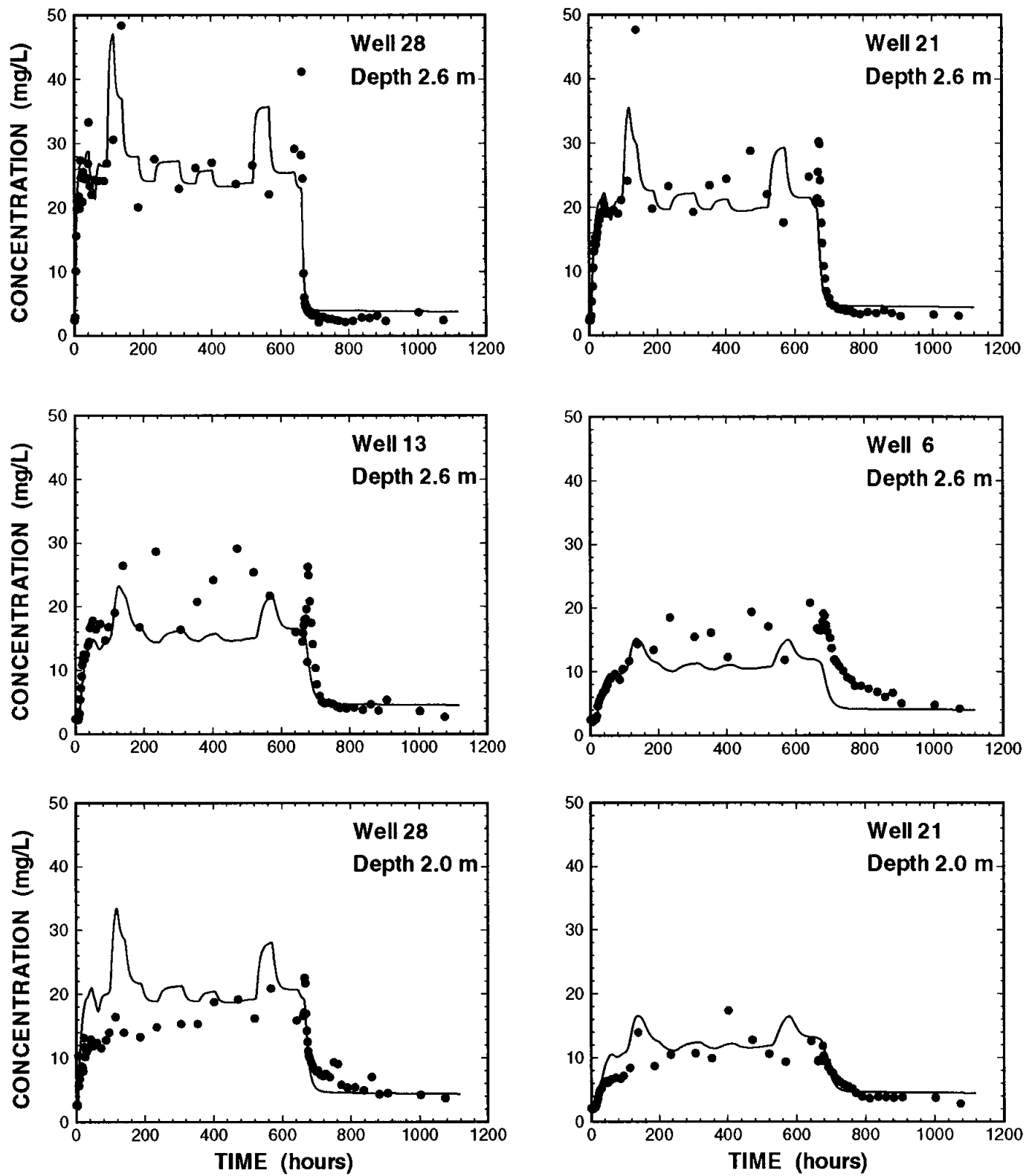

Figure 7a. Observed (solid circles) and simulated (solid line) NOM breakthrough curves at 2.6-m depth (four upper graphs) at 1,2,3, and $4 \mathrm{~m}$ from the injection well and 2.0-m depth (two lower graphs) at 1 and $2 \mathrm{~m}$ from the injection well. The values of the coefficients are $k_{1}=0.75 \times 10^{-3} \mathrm{~min}^{-1}, k_{2}=0.10 \times 10^{-4}$ $\min ^{-1}$, and $k_{3}=0.65$.

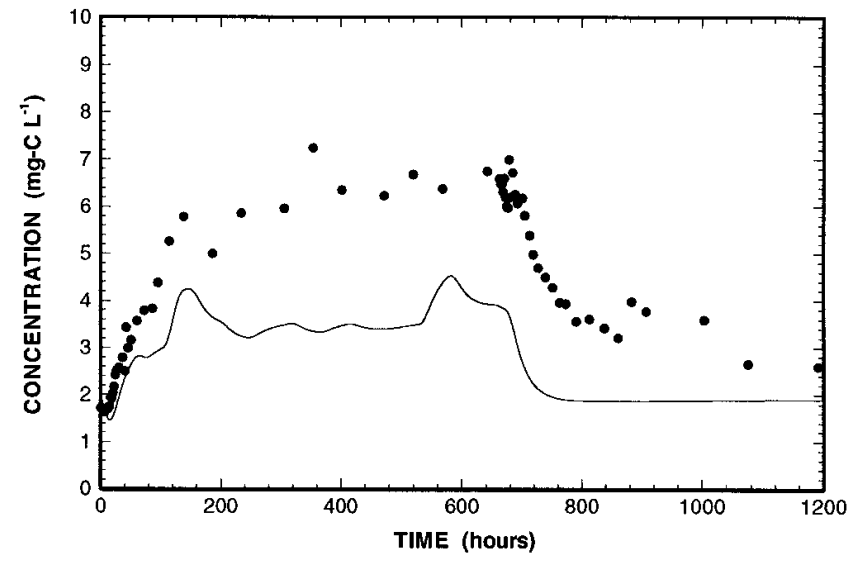

Figure 7b. Same as Figure 7a, except at the withdrawal well. the plateau is increasingly underestimated with distance, even though the ascending limb of the curve was correctly simulated in all sampling points at 2.6-m depth and the withdrawal well, suggesting that a change of the adsorption parameters occurred with time. The same set of coefficients overestimates breakthrough in both sampling ports at the 2.0-m depth, especially at early times. This result would be anticipated based on laboratory isotherms indicating the greater adsorption capacity of this layer.

Comparison of the simulated and observed cumulative concentrations (Figure 6) also illustrates a decrease in observed adsorption over time. The observed cumulative concentrations at the more distant wells deviate in the direction of the 1:1 line from the simulation that assumes constant adsorption. The pattern is particularly clear in the withdrawal well, which provides a more integrated representation of the transport pro- 

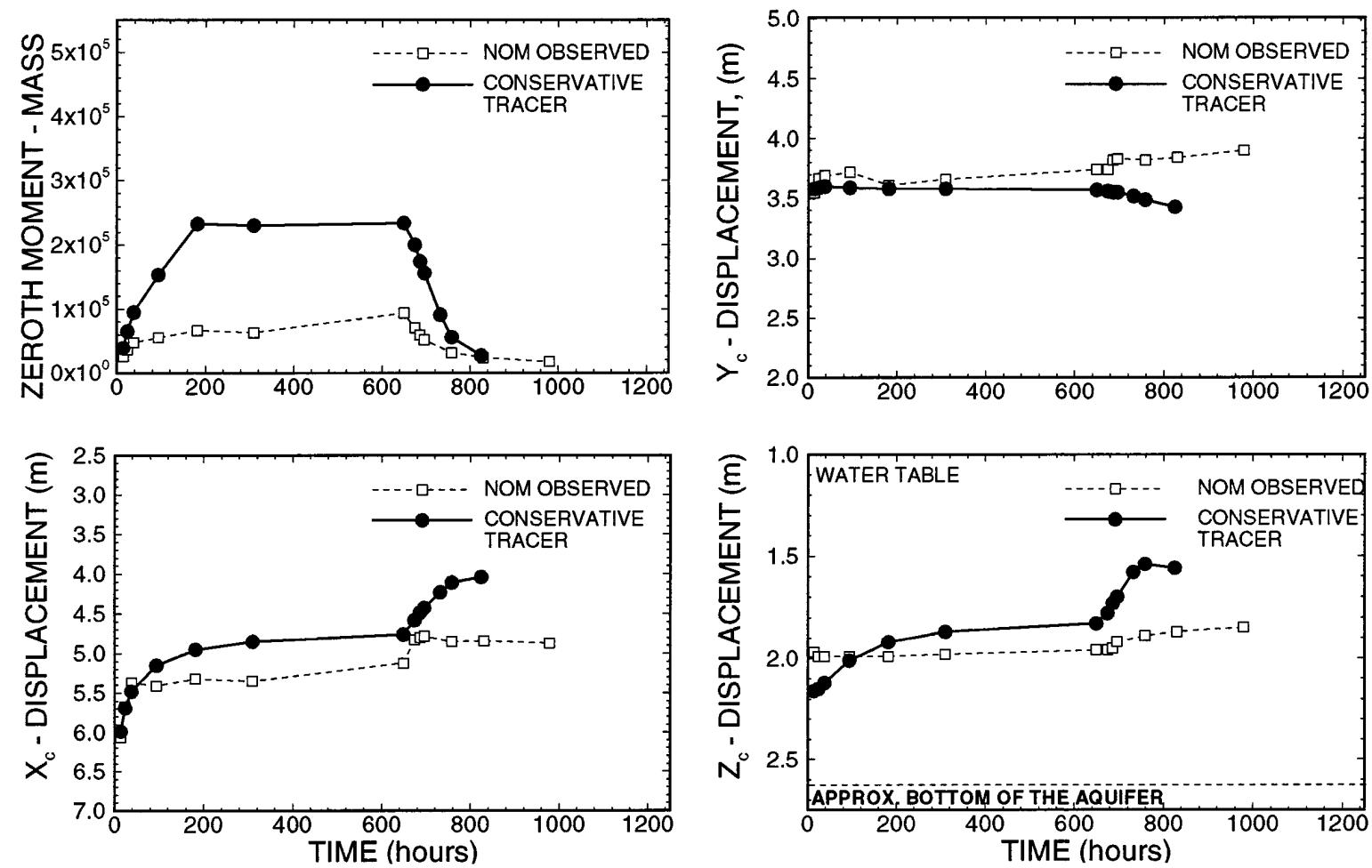

Figure 8. Comparison of the spatial moments of the observed NOM and the simulated plume of conservative tracer. The top left panel is the zeroth moment, or total mass versus time; the remaining panels are the location of the center of mass $\left(x_{c}, y_{c}, z_{c}\right.$, respectively) versus time. The injection well is located at coordinates $(7.0,3.5)$, and the withdrawal well is located at $(2.0,3.5)(\mathrm{m})$.

cess. The decrease in the extent of adsorption over time, which is also suggested by the small but consistent increase in the solution-phase mass of NOM in the domain over time (zeroth spatial moment, Figure 8), is attributed to binding sites on aquifer surfaces gradually becoming saturated as NOM subcomponents with high binding affinity adsorb and displace less strongly bound subcomponents (see below).

Although the two-site model appeared to represent the observed breakthrough of NOM reasonably well over the short distances, the results of this study demonstrate that such simple approaches to modeling NOM transport are inherently inadequate. As will be discussed, NOM is a multicomponent mixture and different subcomponents exhibit markedly different transport properties, and this complexity cannot be represented in models that treat NOM as a single solute.

Moments analysis. Using data from the 18 "snapshots" of the NOM plume, the spatial moments provide an integrated perspective of the migration of the three-dimensional plumes of conservative tracer and NOM (Figure 8). Of greatest interest are the zeroth and first moments of the plumes, which focus on the total solution-phase mass, and the movement of the apparent center of mass along the $x$ axis between the injection and withdrawal wells, respectively.

The mass of NOM in the domain became approximately constant much sooner (at $\sim 60$ hours) than the conservative tracer (at 100 hours). Ideally, a constant mass is reached when the input mass injected in the domain equals that leaving it through its boundaries. The leveling of NOM mass indicates that an additional removal mechanism, adsorption, significantly controlled its distribution, although errors in the simulation of the conservative tracer through the boundaries may also contribute to the mass difference. The mass of solutionphase NOM increases slightly over time, compared with the constant mass of chloride, suggesting that the extent of adsorption decreases during the injection period.

Adsorption is also attributed for the eventual retardation of NOM center of mass moving between the injection and withdrawal wells, as indicated by the analysis of the first moment (Figure 8). At early times, however, both the NOM and conservative tracer moved together along the $x$ direction. At 38 hours, the NOM center of mass even appears slightly ahead of the chloride, although this may result from computational approximations. Nevertheless, the trend indicates that adsorption did not significantly retard the movement of the center of mass during this early period, when the plume was located in the region of maximum flow velocity. After 60 hours, the location of the center of mass of both plumes begins to differentiate, with the NOM retarded $0.5-\mathrm{m}$ behind that of the conservative tracer. This initial conservative movement of NOM may reflect slow adsorption kinetics but are postulated to be due primarily to differences in transport behavior of NOM subcomponents, as will be discussed below.

The spatial moments of the observed chloride and NOM plumes were analyzed [Mas-Pla, 1993], and the pattern was similar to that seen with the simulated chloride. The displacement of both solutes was similar at early times, with faster movement of chloride afterward.

Breakthrough curves from the six sampling wells and the withdrawal well were analyzed by temporal moment analysis to estimate percentage of mass lost and the apparent retardation of NOM (Table 2). These parameters were calculated over the first 1200 hours of the test. In addition, the apparent retarda- 
Table 2. Retardation Analysis of NOM Using Temporal Moments

\begin{tabular}{|c|c|c|c|c|c|c|c|c|c|c|c|}
\hline \multirow[b]{3}{*}{ Well } & \multirow{3}{*}{$\begin{array}{l}\text { Depth, } \\
\text { m }\end{array}$} & \multirow{3}{*}{$\begin{array}{c}\text { Distance, } \\
\mathrm{m}\end{array}$} & \multirow{2}{*}{\multicolumn{3}{|c|}{$\begin{array}{l}\text { Area } \times 10^{7} \\
1200 \text { hours }\end{array}$}} & \multicolumn{6}{|c|}{ Mean Arrival Time } \\
\hline & & & & & & \multicolumn{3}{|c|}{ Over 1200 hours } & \multicolumn{3}{|c|}{ Over 660 hours } \\
\hline & & & $\mathrm{CT}$ & NOM & Loss & $\mathrm{CT}$ & NOM & $R^{*}$ & CT & NOM & $R^{*}$ \\
\hline 28 & 2.6 & 1.0 & 0.120 & 0.099 & $17 \%$ & 336.9 & 347.2 & 6.6 & 323.5 & 328.1 & 10.2 \\
\hline 21 & 2.6 & 2.0 & 0.120 & 0.091 & $24 \%$ & 343.6 & 371.4 & 4.2 & 327.0 & 333.5 & 2.6 \\
\hline 13 & 2.6 & 3.0 & 0.119 & 0.084 & $29 \%$ & 355.1 & 400.7 & 3.3 & 332.6 & 351.2 & 2.9 \\
\hline 6 & 2.6 & 4.0 & 0.109 & 0.065 & $40 \%$ & 369.0 & 481.1 & 4.3 & 338.8 & 371.0 & 3.0 \\
\hline 28 & 2.0 & 1.0 & 0.120 & 0.065 & $45 \%$ & 345.4 & 445.8 & 10.7 & 327.9 & 364.5 & 8.5 \\
\hline 21 & 2.0 & 2.0 & 0.120 & 0.041 & $66 \%$ & 365.2 & 446.7 & 3.7 & 336.9 & 367.6 & 3.2 \\
\hline WW & $\ldots$ & 5.0 & 0.048 & 0.020 & $57 \%$ & 422.5 & 508.2 & 2.3 & 358.5 & 382.8 & 1.7 \\
\hline
\end{tabular}

$\mathrm{CT}$, simulated conservative tracer; WW, withdrawal well. Area is given in $\mathrm{mg} / \mathrm{L} \times \min$. The mean arrival time is given in hours. $R^{*}$, apparent retardation, as described equations (1)-(3). Mean arrival time for the input concentration, $\bar{t}_{A}$ (input), is 335 hours (over 1200 hours) and 323 hours (over 660 hours).

tion of NOM was calculated over the adsorption limb only (660 hours), because of chloride simulation was particularly well reproduced in this portion of the curve [Yeh et al., 1995].

The mass of NOM arriving at monitoring wells (area under the breakthrough curve) decreases with distance from the injection source due to adsorptive losses, and mass losses are significantly greater in the $2.0-\mathrm{m}$ depth (Table 2). Apparent retardation, $R^{*}$, is relatively small in all the wells but is noticeably greater at well 28. Similar values of $R^{*}$ were obtained when only the adsorption limb of the curve was considered. Thus the transport behavior of the bulk NOM is characterized by significant losses of mass, yet with relatively little retardation. The greater retardation at well 28 may be caused by the creation of adsorption sites in a small portion of the aquifer close to the injection well. Even the relatively low concentrations of DO in the injection solution (Table 1b) can promote the slow oxidation of $\mathrm{Fe}$ (II) and precipitation of $\mathrm{Fe}$ (III)-oxide [Liang et al., 1993a, b] which may have enhanced adsorption and increased retardation in a localized region.

Transport of NOM subcomponents. The NOM injection solution and groundwater contained significantly different proportions of the different NOM size fractions. Virtually all of the groundwater NOM was in the $<3000$ molecular weight size fraction, whereas most of the NOM injection solution was in the 3000-100,000 fraction (Table 3). There were significant differences in the relative mobility of $<3000$ and 3000-100,000 fractions arriving at the withdrawal well (Figure 9) well as the other monitoring wells (Figure 10). The breakthrough curve areas, mean arrival times, and apparent retardation factors were calculated (Table 4). Key observations include the following:

Table 3. Characterization of NOM Subcomponents in Groundwater and the NOM Injection Solution

\begin{tabular}{lcc}
\hline & \multicolumn{2}{c}{$\begin{array}{c}\text { NOM Subcomponent, mg C L } \\
\text { (Percent of Total) }\end{array}$} \\
\cline { 2 - 3 } Size Fraction, & Groundwater & $\begin{array}{c}\text { NOM Injection } \\
\text { Solution }\end{array}$ \\
\hline$<3000$ & 1.6 & 11.5 \\
$3000-100,000$ & $(89.6 \%)$ & $(35 \%)$ \\
$>100,000$ & 0.19 & 17.2 \\
& $(10.4 \%)$ & $(52 \%)$ \\
& 0 & 4.3 \\
& $(0 \%)$ & $(13 \%)$ \\
\hline
\end{tabular}

1. The $<3000$ fraction appears to be transported almost conservatively during the NOM injection, with a plateau similar to that for the conservative tracer (Figure 9). Although the calculated mass area arriving at the withdrawal well suggests that there was a significant loss of the $<3000$ NOM (Table 4), that result may be influenced by the sparse sampling of the size fractions, which missed many of the input concentration peaks that were included by the chloride simulation. The similarity in the transport of $<3000 \mathrm{NOM}$ and the nonreactive tracer observed in the withdrawal well is also apparent at the other monitoring wells. Chloride and the $<3000$ NOM lost a similar proportion of mass at wells progressively more distant from the injection well (i.e., the slopes of the conservative tracer and the $<3000$ NOM are similar in Figure 10).

2. The shape of the breakthrough curve for the bulk NOM at the withdrawal well appears to result primarily from its dominant fraction, the 3000-100,000 fraction. This is also reflected in the similar proportion of mass loss for the bulk NOM and the 3000-100,000 fraction at wells progressively more dis-

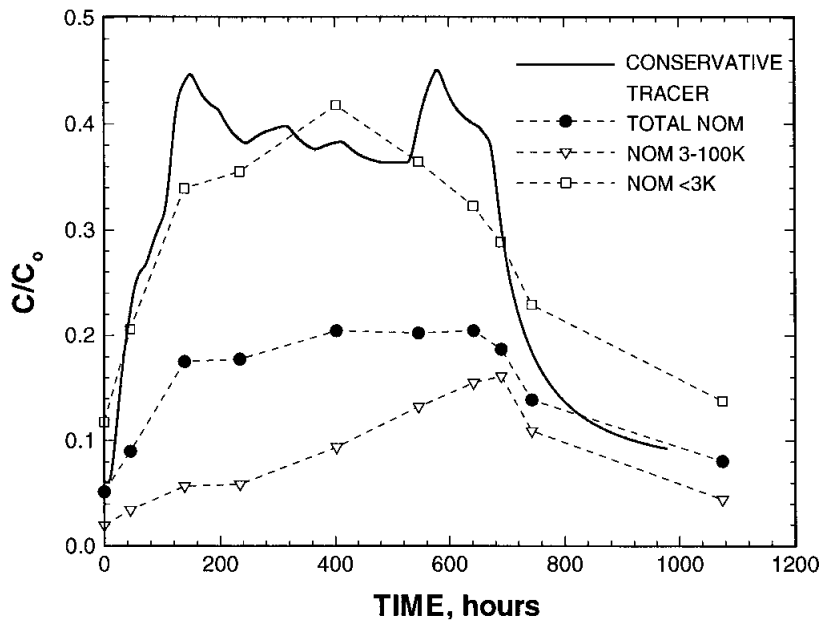

Figure 9. Observed normalized breakthrough curves for bulk NOM and the $<3000$ and 3000-100,000 NOM size fractions at the withdrawal well. The simulated breakthrough curve for the conservative tracer (solid line) is included for comparison. $C_{0}$ represents the mean concentration of bulk NOM in the injection solution ( $33 \mathrm{mg} \mathrm{C} \mathrm{L}^{-1}$ ), or the concentration of the two subcomponents in the NOM injection solution $(11.55$ $\mathrm{mg} \mathrm{C} \mathrm{L} \mathrm{L}^{-1}$ for $<3000 \mathrm{NOM}$ and $17.16 \mathrm{mg} \mathrm{C} \mathrm{L}^{-1}$ for the 3000-100,000 NOM). 


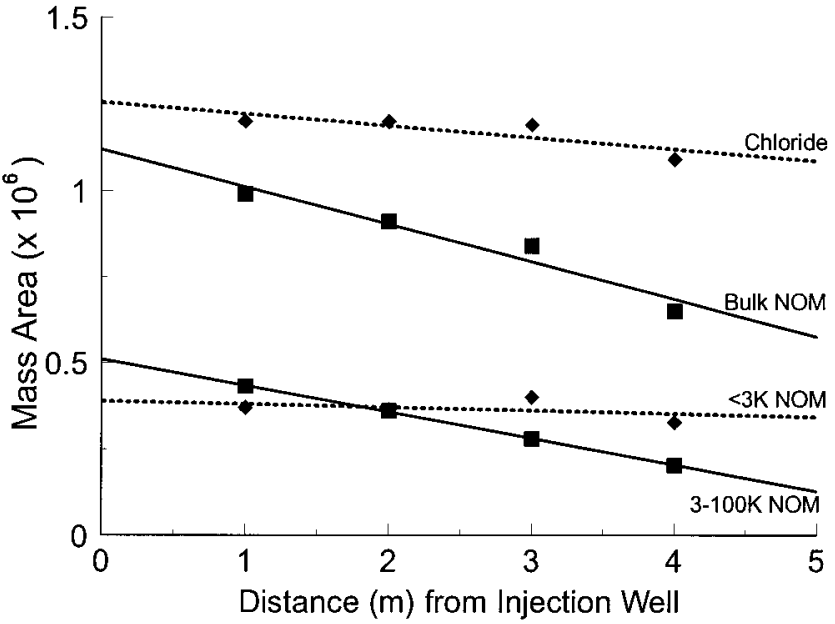

Figure 10. The mass of conservative tracer and NOM subcomponents arriving at monitoring wells located 1, 2, 3, and 4 $\mathrm{m}$ from the injection well at the 2.6- $\mathrm{m}$ depth.

tance from the injection well (i.e., the slopes are similar in Figure 10). In contrast to the $<3000$ fraction, breakthrough of the 3000-100,000 NOM is characterized by extended tailing of the ascending limb (Figure 9). There is a much greater loss of mass area the 3000-100,000 fraction than the $<3000$ NOM (Table 4 and Figure 10).

3. The $>100,000$ fraction remains a minor component, constituting only a few percent of the mobile NOM (data not shown).

4. Retardation factors (Table 4) are consistent with the observed behavior of each component. The $<3000$ fraction moved with little retardation, and the center of mass arrived at approximately the same time as the conservative tracer. The 3000-100,000 NOM was much more retarded.

5. The heterogeneity in the transport behavior of NOM subcomponents was also evident when NOM was analyzed with respect to other properties, including hydrophobicity and UV/VIS absorbance spectra (data not shown).

These results demonstrate that NOM transport must be understood in terms of the chemical heterogeneity of NOM, rather than its bulk behavior. The transport behavior of the bulk material, which exhibited relatively little retardation but large loss of mass (Figure 8 and Table 2), could be described within the context of a transport model as predictable behavior of a single solute. In a comparison of models describing the transport of NOM in aquifer column studies, Jardine et al. [1992] attributed the extended tailing of the breakthrough curves for the bulk NOM to slow, time-dependent adsorption. Yet, at the field scale the two-site model (which did include kinetically controlled, nonequilibrium adsorption) was unable to fully account for the shape of the NOM breakthrough curves. Kinetic limitations, arising either from slow rates of adsorption or from slow diffusive mass transfer of NOM to less accessible binding sites (dead-end pores or inclusions of finegrained material within the coarse sand at the 2.6-m depth), might be expected to be of limited importance at the spatial and temporal scales of this field experiment. It seems more likely that the transport behavior of the bulk NOM is due primarily to the multicomponent nature of NOM and the large differences observed in the mobility of the NOM subcomponents (Figure 9 and Table 4). The low retardation reflects the conservative behavior of the $<3000$ NOM, while the higher molecular weight NOM accounts for the adsorptive losses.

The observation that different size fractions of NOM exhibit very different transport behavior is consistent with observations of Davis and Gloor [1981] and Gu et al. [1995] that higher molecular weight components of NOM have a greater affinity for adsorption to mineral oxides and with previous field observations of NOM transport [McCarthy et al., 1993]. Gu et al. [1995] determined isotherms for adsorption of size fractions of Georgetown NOM on iron oxide because this mineral was expected to be the dominant adsorptive phase in the ironcoated sands at Georgetown. The adsorption affinity and capacity of the $<3000 \mathrm{NOM}$ were lower than that of the larger size fraction, but only by $\sim 20 \%$. This relatively small difference observed in laboratory studies is not consistent with the very large differences in the transport behavior of the size fractions in the field (Figure 9). The limited adsorption of the $<3000$ fraction in the aquifer is postulated be due to "passivation" of the aquifer by previously adsorbed components of groundwater NOM. Almost all of the NOM in the Georgetown groundwater is $<3000$ molecular weight and aquifer surfaces may be saturated with respect to their capacity to adsorb NOM subcomponents in this fraction. Although the groundwater NOM and the $<3000 \mathrm{NOM}$ in the injection solution are unlikely to have identical chemical composition, their adsorption behaviors are postulated to be similar and result in little additional adsorption of this fraction during the injection. The 3000100,000 fraction has a higher adsorption affinity for aquifer surfaces, and its retention by the aquifer is postulated to occur through competitive displacement of previously adsorbed $<3000$ NOM.

The behavior of NOM in the injection experiment is interpreted as the introduction of a multicomponent NOM mixture into a porous media previously equilibrated with groundwater NOM of different composition. Clear differences in the mobility of two operationally defined fractions of NOM illustrated this phenomenon. Since the aquifer sediments were equilibrated with the groundwater NOM prior to the experiment, only small amounts of the $<3000$ NOM in the injection solution was adsorbed, and migration was essentially conservatively

Table 4. Differences in the Transport Behavior of NOM Size Fractions Arriving at the Withdrawal Well

\begin{tabular}{lccc}
\hline & $<3000$ & $3000-100,000$ & CT \\
\hline \multicolumn{3}{c}{ Over 1200 Hours } \\
Breakthrough curve areas & 0.087 & 0.006 & \\
Area $\times 10^{6 a}$ & 48 & 98 \\
Mass loss, ${ }^{\text {b } \%}$ & Over 660 Hours & \\
Mean arrival time $^{\mathrm{c}}$ & 357.4 & 526.4 & 358.5 \\
Apparent retardation $^{\mathrm{d}}$ & $\cdots$ & 5.73 & \\
\hline
\end{tabular}

a Area is given in $\mathrm{mg} \mathrm{L}^{-1} \mathrm{~min}^{-1}$. The input concentration curve area for bulk NOM is $0.1219 \times 10^{7}$, for $<3000$ is $0.420 \times 10^{6}$, and for $3000-100,000$ is $0.634 \times 10^{6} \mathrm{mg} \mathrm{L}^{-1} \mathrm{~min}^{-1}$.

${ }^{\mathrm{b}}$ To account for dilution and other nonreactive losses along the flow path, the loss of mass is calculated as $\%$ loss $=\left(\left(\right.\right.$ Area $_{\mathrm{CT}} *$ Fraction $\left._{\text {size }}\right)$ - Area $\left._{\text {size }}\right) /\left(\right.$ Area $_{\mathrm{CT}} *$ Fraction $\left._{\text {size }}\right) \times 100 \%$, where Area ${ }_{\mathrm{CT}}$ is the mass area of conservative tracer (Table 2), Fraction size $_{\text {is }}$ the fraction of the bulk NOM in a given size fraction (Table 3), and Area size $_{\text {is }}$ the mass area of the size fraction arriving at the withdrawal well.

'The mean arrival time is given in hours.

${ }^{\mathrm{d} A p p a r e n t}$ retardation, using equations (1)-(3). Mean arrival time for the input concentration (over 660 hours) $=323.0$ hours (Table 2 ). 
during the NOM injection. The experiment introduced novel NOM subcomponents into an aquifer in which binding sites on mineral surfaces were occupied by NOM subcomponents derived from the groundwater. Retention of the novel NOM required competitive displacement of more weakly binding components of the groundwater NOM by higher-affinity NOM subcomponents in the injection solution. When the NOM injection was terminated, concentration of $<3000 \mathrm{NOM}$ in the groundwater decreased and some desorption of this weakly bound material occurred. Strongly bound NOM subcomponents desorbed only to a limited extent. These subcomponents, having displaced the more readily desorbed NOM over the course of the injection, represent the bulk of the adsorbed NOM. Thus the apparent "irreversibility" of NOM adsorption is the consequence of adsorption and desorption of NOM subcomponents with range of binding affinities. The "hysteresis" may reflect very limited, but fully reversible, desorption of those more strongly binding subcomponents. The interpretation of the field data in terms of competitive interactions is consistent with the laboratory results of $G u$ et al. [1996a, b], who demonstrated the competitive adsorption of NOM and model organic solutes, and competitive displacement of weakly binding organics by those with stronger binding affinities. Because of difficulties in distinguishing which subcomponents of NOM adsorbed to surfaces, model organic compounds with functional groups and molecular structures similar to those in NOM (polyacrylic acid, phthalic acid, and salicylic acid) were used in binary adsoption studies with NOM. The competition among the organic compounds was related to their ionizable functional groups and molecular structure. For example, polyacrylic acid was more competitive than the other compounds, possibly because its high carboxyl density and linear molecular structure form stronger surface complexes with the model iron oxide sorbent [Gu et al., 1996a, b].

The current study demonstrates that for many purposes, predictive modeling of NOM transport needs to consider its chemical complexity, although this may be problematic. The rationale for studies of NOM transport often derives from concerns about its potential effect on several processes, including facilitated transport of organic or inorganic contaminants bound to the NOM [Dunnivant et al., 1992b; Enfield et al., 1989; Kan and Tomson, 1990], the stability and transport of inorganic colloids [Liang et al., 1993a; Amirbahman and Olson, 1993], or its potential effect on the chemical stability (formation and dissolution) of mineral oxides [Ryan and Gschwend, 1990; Liang et al., 1993b]. Yet different subcomponents of NOM affect these processes differently. Larger, more hydrophobic, and more aromatic NOM has a higher affinity for binding organic contaminants [Gauthier et al., 1987; Traina et al., 1989; McCarthy et al., 1989; Kukkonen et al., 1990, 1991], while complexation of metals and radionuclides might be significant for hydrophilic components of NOM, which have higher oxygento-carbon ratios and are enriched in carboxylic functional groups [Aiken et al., 1992; Marinsky and Ephraim, 1986; Perdue, 1989; Nash et al., 1981]. Likewise, transport of NOM-coated iron oxide colloids in porous media appeared to be inversely related to the acidity, oxygen-to-carbon ratio, and molecular size of the adsorbed NOM [Amirbahman and Olson, 1993]. Descriptions of NOM transport must consider the changes in the functional properties of the NOM in the mobile phase (and potentially capable of facilitating transport of contaminants) and NOM retained on surfaces (and capable of enhancing the adsorptive capacity of the aquifer or of mobilizing inorganic colloids).

Unfortunately, the state of science with respect to multicomponent chemical modeling is not sufficiently advanced to adequately describe the adsorptive and transport behavior of a complex mixture such as NOM. Representation of NOM as a number of discrete solutes with defined single-component adsorption isotherms is not possible because the huge array of individual NOM molecules can not be isolated or characterized, nor can the functional behavior of NOM be described at a molecular level. Several approaches to reducing the complexity of multicomponent systems have been attempted. Complex multicomponent systems have been represented as a continuum, in which the true multicomponent discrete system is replaced with a continuous mixture containing an infinite number of components and described through a distribution function of variables that characterize the multicomponent adsorption equilibria (e.g., extended Langmuir equation or ideal adsorbed solution theory [Okasaki et al., 1981; Annesini et al., 1988]). Alternately, solutions containing a large number of adsorbates of unknown composition have been represented as a solution with a few "pseudospecies," i.e., a finite number of groups of solutes defined as having similar, discrete adsorption behavior [Jayaraj and Tien, 1985; Kage and Tien, 1987; Moon et al., 1991]. These approaches have limitations as applied to modeling of NOM. First, while such complex multiparameter models could perhaps provide a better fit to observed breakthrough curves for the bulk material than simpler singlecomponent models, they cannot represent or predict the transport of NOM subcomponents with different functional properties of significance to the environmental processes discussed above. In addition, none of the models takes into account the competition among NOM subcomponents for adsorption when adsorption sites on aquifer surfaces are limited; the competitive displacement of weakly binding components of groundwater NOM by higher-affinity subcomponents is postulated to be a key process controlling NOM transport.

While it may not be currently possible to model the complexities of multicomponent competitive NOM interactions, the another important conclusion of this study is that for many environmental scenarios, such modeling may not be necessary to predict the role of NOM in contaminant transport. The complexity described above arises from introduction of a novel NOM source (in this case, the injected wetland pond water) into an aquifer containing groundwater NOM of a different composition. That scenario would be relevant, for example, in situations in which organic matter was codisposed with contaminants, such as at landfills or waste burial sites. Changes in aqueous chemistry (e.g., altered $p \mathrm{H}$ or ionic composition) due to natural or anthropogenic processes might also be expected to disrupt the equilibrium between solid and solution phase NOM and to induce a complex competitive redistribution of NOM subcomponents. Gu et al. [1996a] demonstrated that the competitive adsorption of NOM and model organic compounds is $p \mathrm{H}$-dependent; for example, polyacrylic acid inhibited the adsorption of NOM to iron oxide above $p \mathrm{H}$ above 4, whereas it lost its competitiveness at lower $p \mathrm{H}$.

However, many other contaminant mobilization scenarios do not involve introduction of novel organic matter or changes in aqueous chemistry. For example, transuranic (TRU) radionuclides migrating in groundwater downgradient from shallow TRU storage trenches at the Oak Ridge National Laboratory were shown to be complexed with groundwater NOM. It is 
postulated that seasonal increases in the water elevation of the groundwater intersect the shallow trenches, permitting the groundwater NOM to complex and cotransport the actinides in the waste [McCarthy et al., 1995]. In a groundwater situation such as this, disturbance to the equilibrium between solid and solution phase NOM may be minimal, and the results from the current study (Figure 9) suggest that the transport of the NOM-contaminant complex may be approximated as that of a conservative solute. Contaminants bound to groundwater NOM can therefore be expected to exhibit greatly enhanced mobility. Extended contact will eventually bring even a novel source of NOM into a steady state with respect to adsorption by the aquifer, and contaminants bound to the novel NOM can then be expected to travel conservatively. This principle was demonstrated in laboratory columns by Dunnivant et al. [1992b]. After "passivating" adsorption surfaces by batchcontacting Georgetown aquifer material with NOM-rich water from the wetland pond, they introduced a step input of different concentrations of that NOM with organic and inorganic contaminants (a polychlorinated bipheny and cadmium) onto columns of the NOM-equilibrated aquifer material. Contaminant mobility increased with the solution NOM concentration, and the enhanced contaminant mobility could be explained by incorporating a three-phase system (contaminants distributed between one stationary and two mobile phases: the aqueous phase and a conservatively transported NOM-bound phase) in the convection-dispersion (CD) transport equation. While the association of a metal or organic contaminant with an NOM molecule could affect the transport properties of that NOM molecule (e.g., alter its charge density or size), this effect did not appear important in the Dunnivant et al. [1992b] study.

\section{Summary and Conclusions}

The field-scale transport of NOM was determined in a twowell forced gradient injection experiment in a sandy aquifer. The site characterization, nonreactive tracer tests, and threedimensional flow model [Mas-Pla, 1993; Yeh et al., 1995] made it possible to identify and obtain quantitative estimates of chemical processes controlling NOM transport at the field scale in a way that was not possible in the 1990 field experiment [McCarthy et al., 1993]. Transport was greater in more hydraulically conductive layers at the 2.6-m depth, but mass loss of NOM was greater at the $2.0-\mathrm{m}$ depth due to higher adsorption affinity of the sediments and possibly greater hydrodynamic dispersion arising from the greater physical heterogeneity in this layer. Several features of NOM transport were difficult to reconcile with laboratory studies of adsorption or with conceptualization of NOM as a single entity. The transport behavior of the bulk NOM was characterized by significant losses of mass. Yet the NOM plume comigrated with the conservative tracer for the first few days (Figure 8) and overall retardation was relatively low (Table 2). While this is consistent with a kinetically controlled adsorption process, the large differences in the transport behavior of different NOM subcomponents suggest the multicomponent nature of NOM may be the principal underlying cause of this behavior. There appeared to be a strong adsorption-desorption hysteresis, since the desorption curves for bulk NOM were similar to those of the conservative solute. However, the apparent "irreversibility" of NOM adsorption is postulated to be the consequence of adsorption and desorption of NOM subcomponents with range of binding affinities. The "hysteresis" may reflect very limited, but fully reversible, desorption of those more strongly binding subcomponents.

An important conclusion of this study is the recognition that NOM is ubiquitous in natural subsurface systems, and coatings of autochthonous NOM on aquifer surfaces can have a significant effect on the retention of NOM subcomponents. Better descriptions of NOM transport require improved understanding of competitive adsorption of NOM on surfaces. Such understanding must include consideration of the chemical heterogeneity of the NOM subcomponents (and of aquifer binding sites), which gives rise to a range of adsorptive affinities that control the nature and amount of NOM retained on surfaces or transported in groundwater.

These results emphasize the need to conceive of some NOM transport problems as a multicomponent transport process involving competitive adsorption of subcomponents for binding sites. Introduction of NOM that differs from autochthonous groundwater NOM with respect to the nature or amount of NOM subcomponents will induce disequilibria between the solution and solid phase NOM, with the release of weakly binding components and retention of strongly binding NOM. The chemical properties and, more importantly, the functional behavior of NOM with respect to contaminant migration or the stability of inorganic colloidal phases will vary with time and distance along a flow path. Additional disequilibria in NOM adsorption and colloid stability may also be induced by changes in $p \mathrm{H}$ or ionic composition along flow paths. Predictive modeling of these dynamic competitive interactions along a flow path is problematic.

However, in the absence of chemical disequilibria (either as introduction of novel NOM or changes in aqueous chemistry), it may be possible to model the role of NOM on contaminant transport much more simply. When groundwater NOM exists at a steady state with respect to adsorption on aquifer surfaces or in portions of a flow path where prolonged inputs of a "novel" source of organic matter eventually saturate binding sites for the new NOM, results of this study suggest that the transport of NOM, and the contaminant-NOM complex, may be approximated as the transport of a conservative solute.

One objective of the field study was to test laboratory understanding and focus laboratory research on issues that may not have been previously recognized as important. In this, the field experiment was successful. While column studies using site-specific material [Dunnivant et al., 1992a] demonstrated differences in the mobility of NOM subcomponents, a singlespecies solute model could reproduce the NOM breakthrough curve over the short times and distances of the column studies [Jardine et al., 1992]. The larger scale of the field experiment clarified the importance of the multicomponent nature of NOM transport: the mobile components of NOM could be better characterized in the larger-volume field samples, and the spatial and temporal scale of the field experiment demonstrated the conceptual and operational failure of single-species solute models more conclusively than did the results of the column studies. Discrepancies between the laboratory and field results were also informative. For example, the discrepancy between the adsorption of NOM subcomponents on a model sorbent that lacked any previously adsorbed NOM [ Gu et al., 1995] and field results lead to our hypothesis that previous coatings of NOM on surfaces controlled NOM adsorption and transport behavior in the field. This field-derived hypothesis has now been confirmed in laboratory studies on the competitive interactions among NOM and model organic com- 
pounds [Gu et al., 1996a, b]. It should noted that an earlier field experiment on NOM transport [McCarthy et al., 1993] was far less successful in testing understanding of NOM transport processes due to uncertainties arising from limited information on the flow field. Heterogeneity in the aquifer required highresolution information on the spatial distribution of hydrologic properties of the aquifer [Yeh et al., 1995] in order to properly resolve the chemical, as opposed to hydrologic factors that controlled the transport of NOM.

Acknowledgments. The Oak Ridge National Laboratory (ORNL) is managed by Lockheed Martin Energy Research Corporation for the U.S. Department of Energy (DOE) under contract DE-AC05960R22464. This field research required the hard work of many dedicated researchers, including L. W. Jolley, C. McCutcheon, J. A. McDonald, J. A. McNabb, and T. W. Melhorn, and their efforts are greatly appreciated. We also thank E. M. Perdue and C. Tien for their insights into the multicomponent nature of the NOM transport process, S. Yiacoumi for discussions on approaches to multicomponent modeling NOM transport, D. K. Solomon for advice and discussion on physical aspects of transport, and P. M. Jardine and L. Song for valuable comments and insights in reviewing this manuscript. Funding for this research was provided by the Subsurface Science Program, Environmental Sciences Division, DOE, and the support of the Program Manager, F. J. Wobber, is appreciated. Mas-Pla was also supported in part by "Fundacio La Caixa" (Barcelona, Spain) during his stay at the Department of Hydrology and Water Resources at the University of Arizona where the modeling work was performed. Publication 4510 of the Environmental Sciences Division of ORNL.

\section{References}

Aiken, G. R., D. M. McKnight, K. A. Thorn, and E. M. Thurman, Isolation of hydrophilic organic acids from water using nonionic macroporous resins, Org. Geochem., 18(4), 567-573, 1992.

Amirbahman, A., and T. M. Olson, Transport of humic matter-coated hematite in packed beds, Environ. Sci. Technol., 27, 2807-2813, 1993.

Annesini, M. C., F. Gironi, and L. Marrelli, Multicomponent adsorption of continuous mixtures, Ind. Eng. Chem. Res., 27, 1212-1217, 1988.

Boggs, J. M., and E. E. Adams, Field study of dispersion in a heterogeneous aquifer: Investigation of adsorption and sampling bias, Water Resour. Res., 28(12), 3325-3336, 1992.

Cameron, D. A., and A. Klute, Convective-dispersive solute transport with a combined equilibrium and kinetic adsorption model, Water Resour. Res., 13, 183-188, 1977.

Davis, J. A., and R. Gloor, Adsorption of dissolved organics in lake water by aluminum oxide, effect of molecular weight, Environ. Sci. Technol., 15, 1223-1228, 1981.

Dunnivant, F. M., P. M. Jardine, D. L. Taylor, and J. F. McCarthy, Transport of naturally-occurring dissolved organic carbon in laboratory columns containing aquifer material, Soil Sci. Soc. Am. J., 56, 437-443, 1992a.

Dunnivant, F. M., P. M. Jardine, D. L. Taylor, and J. F. McCarthy, The co-transport of cadmium and hexachlorobiphenyl by dissolved organic matter through columns of aquifer material, Environ. Sci. Technol., 26, 360-368, 1992b.

Enfield, C. G., G. Bengtsson, and R. Lindqvist, Influence of macromolecules on chemical transport, Environ. Sci. Technol., 23, 1278 1286, 1989.

Gauthier, T. D., W. R. Seitz, and C. L. Grant, Effects of structural and compositional variations of dissolved humic materials on pyrene $K_{\mathrm{oc}}$ values, Environ. Sci. Technol., 21, 243-248, 1987.

Gu, B., J. Schmitt, Z. Chen, L. Liang, and J. F. McCarthy, Adsorptiondesorption of natural organic matter on iron-oxide: Mechanisms and models, Environ. Sci. Technol., 28, 38-46, 1994.

Gu, B., J. Schmitt, Z. Chen, L. Liang, and J. F. McCarthy, Adsorption and desorption of different organic matter fractions on iron-oxide, Geochim. Cosmochim. Acta, 59(2), 219-229, 1995.

Gu, B., T. Mehlhorn, L. Liang, and J. F. McCarthy, Competitive adsorption, displacement, and transport of organic matter on iron oxide, I, Competitive adsorption, Geochim. Cosmochim. Acta, in press, 1996a.
Gu, B., T. Mehlhorn, L. Liang and J. F. McCarthy, Competitive adsorption, displacement, and transport of organic matter on iron oxide, II, Displacement and transport, Geochim. Cosmochim. Acta, in press, $1996 \mathrm{~b}$.

Jardine, P. M., F. M. Dunnivant, H. M. Selim, and J. F. McCarthy, Comparison of models for describing the transport of dissolved organic carbon in laboratory columns containing aquifer material, Soil Sci. Soc. Am. J., 26, 393-401, 1992.

Jayaraj, K., and C. Tien, Characterization of adsorption affinity of unknown substances in aqueous solutions, Ind. Eng. Chem. Process Des. Dev., 24, 1230-1239, 1985.

Kage, H., and C. Tien, Further development of the adsorption affinity characterization procedure for aqueous solutions with unknown compositions, Ind. Eng. Chem. Res., 26, 284-292, 1987.

Kan, A. T., and M. B. Tomson, Ground water transport of hydrophobic organic compounds in the presence of dissolved organic matter, Environ. Toxicol. Chem., 9, 253-263, 1990.

Kukkonen, J., J. F. McCarthy, and A. Oikari, Effects of XAD-8 fractions of dissolved organic carbon on the sorption and bioavailability of organic micropollutants, Arch. Environ. Contam. Toxicol., 19, 551-557, 1990 .

Kukkonen, J., J. F. McCarthy, and A. Oikari, Binding and bioavailability of organic micropolutants in natural waters: Effects of quality and quantity of dissolved organic material, in Organic Substances and Sediments in Water, edited by R. A. Baker, pp. 111-128, Lewis, Chelsea, Mich., 1991.

Liang, L., J. F. McCarthy, L. W. Jolley, J. A. McNabb, and T. W. Mehlhorn, Iron dynamics: Transformation of $\mathrm{Fe}(\mathrm{II}) / \mathrm{Fe}(\mathrm{III})$ during injection of natural organic matter in a sandy aquifer, Geochim. Cosmochim. Acta, 57, 1987-1999, 1993a.

Liang, L., J. A. McNabb, J. M. Paulk, B. Gu, and J. F. McCarthy, Kinetics of $\mathrm{Fe}(\mathrm{II})$ oxygenation at low partial pressure of oxygen and in the presence of natural organic matter, Environ. Sci. Technol., 27, 1864-1870, 1993b.

Magee, B. R., L. W. Lion, and A. T. Lemely, The transport of dissolved organic macromolecules and their effect on the transport of phenanthrene in porous media, Environ. Sci. Technol., 25, 323-331, 1991.

Marinsky, J. A., and J. Ephraim, A unified physicochemical description of the protonation and metal ion complexation equilibria of natural organic acids (humic and fulvic acids), 1, Analysis of the influence of polyelectrolyte properties on protonation equilibria in ionic media: Fundamental concepts, Environ. Sci. Technol., 20, 349-354, 1986.

Mas-Pla, J., Modeling the transport of natural organic matter in heterogeneous porous media: Analysis of a field-scale experiment at the Georgetown site, South Carolina, Ph.D. thesis, Univ. of Ariz., Tucson, 1993.

Mas-Pla, J., T.-C. Jim Yeh, J. F. McCarthy, and T. M. Williams, Numerical simulation of a two-well tracer experiment, Ground $\mathrm{Wa}$ ter, 30, 958-964, 1992.

McCarthy, J. F., and J. M. Zachara, Subsurface transport of contaminants, Environ. Sci. Technol., 23, 496-503, 1989.

McCarthy, J. F., L. E. Roberson, and L. E. Burris, Association of benzo(a)pyrene with dissolved organic matter: Prediction of $\mathbf{K}_{\mathrm{dom}}$ from structural and chemical properties of the organic matter, Chemosphere, 19, 1911-1920, 1989.

McCarthy, J. F., T. M. Williams, L. Liang, P. M. Jardine, A. V. Palumbo, L. W. Jolley, L. W. Cooper, and D. L. Taylor, Mobility of natural organic matter in a sandy aquifer, Environ. Sci. Technol., 27, 667-676, 1993.

McCarthy J. F., J. D. Marsh, and E. Tipping, Mobilization of actinides from disposal trenches by natural organic matter, paper presented at the 209th Annual Meeting, Am. Chem. Soc., Anaheim, Calif., 1995.

Moon, H., H. C. Park, and C. Tien, Adsorption of unknown substances from aqueous solutions, Chem. Eng. Sci., 46, 23-31, 1991.

Murphy, E. M., J. M. Zachara, S. C. Smith, J. L. Phillips, and T. W. Wietsma, Interactions of hydrophobic organic compounds with mineral-bound humic substances, Environ. Sci. Technol., 28, 1291-1299, 1994.

Nash, K., S. Fried, A. M. Friedman, and J. C. Sullivan, Redox behavior, complexing, and adsorption of hexavalent actinides by humic acid and selected clays, Environ. Sci. Technol., 15, 834-837, 1981.

Okazaki, M., H. Kage, F. Iijima, and R. Toei, Approximate description of multi-solute adsorption equilibrium in organic aqueous solution, J. Chem. Eng. Jpn., 14, 26-31, 1981.

Perdue, E. M., Effects of humic substances on metal speciation, in Aquatic Humic Substances: Influence on Fate and Treatment of Pol- 
lutants, edited by I. H. Suffet and P. MacCarthy, pp. 281-296, Am. Chem. Soc., Washington, D. C., 1989.

Rajaram H., and L. W. Gelhar, Three-dimensional spatial moments analysis of the Borden tracer test, Water Resour. Res., 27, 1239-1251, 1991.

Roberts, P. V., M. N. Goltz, and D. M. Mackay, A natural gradient experiment on solute transport in a sand aquifer, 3, Retardation estimates and mass balances for organic solutes, Water Resour. Res. 22, 2047-2058, 1986

Ryan, J. N., and P. M. Gschwend, Colloid mobilization in two Atlantic Coastal Plain aquifers, Water Resour. Res., 26, 307-322, 1990.

Srivastava, R., and T.-C. J. Yeh, A three-dimensional numerical model for water flow and transport of a chemically reactive solute through porous media under variably saturated conditions, $A d v$. Water Resour., 15(5): 275-287, 1992.

Stevenson, F. J., and K. M. Goh, Infrared spectra of humic acids and related substances, Geochim. Cosmochim Acta, 35, 417-483, 1971.

Thurman, E. M., Organic Geochemistry of Natural Waters, 495 pp., Marcus Nijhoff, Dordrecht, Netherlands, 1985.

Traina, S. J., J. Novak, and N. E. Smeck, An ultraviolet absorbance method of estimating the percent aromatic carbon content of humic acids, J. Environ. Qual., 19, 151-153, 1989.

Valocchi, A. J., Validity of the local equilibrium assumption for modeling sorbing solute transport through homogeneous soils, Water Resour. Res., 21(6), 808-820, 1985.

Williams, T. M., and J. F. McCarthy, Field scale tests of colloid- facilitated transport, in National Research and Development Conference on Control of Hazardous Materials, pp. 179-184, Hazardous Mater. Control Inst., Greenbelt, Md., 1991.

Yeh, T.-C., Mas-Pla, J., T. M. Williams, and J. F. McCarthy, Observation and three-dimensional simulation of chloride plumes in a sandy aquifer under forced gradient conditions, Water Resour. Res., 31, 2141-2159, 1995.

Zsolnay, A., Effect of an organic fertilizer on the transport of the herbicide atrazine in soil, Chemosphere, 24(5), 663-669, 1992.

B. Gu, L. Liang, and J. F. McCarthy, Environmental Sciences Division, Oak Ridge National Laboratory, P.O. Box 2008, Oak Ridge, TN 37831-6036. (e-mail: jjj@ornl.gov)

J. Mas-Pla, Department de Geologia, Universitat Autonoma de Barcelona, 08193 Bella Terra, Barcelona, Spain. (e-mail: pep@catap. uab.es)

T. M. Williams, Baruch Forest Science Institute, Clemson University, Clemson, SC 29631.

T.-C. J. Yeh, Department of Hydrology and Water Resources, University of Arizona, Bldg. 11, Tucson, AZ 85721. (e-mail: ybiem@mac. hwr.arizona.edu)

(Received September 1, 1995; revised January 10, 1996; accepted January 22, 1996.) 